\title{
An Investigative Study of Factors Influencing Dining out in Casual Restaurants Among Young Consumers
}

\author{
Vimal Chandra Verma ${ }^{1}$, Devashish Das Gupta ${ }^{2}$ \\ ${ }^{1}$ School of Management, BBD University, Lucknow, India \\ ${ }^{2}$ Indian Institute of Management Lucknow, Lucknow, India
}

Email address:

vimalchandraverma@gmail.com (V. C. Verma), devashish@iiml.ac.in (D. D. Gupta)

\section{To cite this article:}

Vimal Chandra Verma, Devashish Das Gupta. An Investigative Study of Factors Influencing Dining out in Casual Restaurants Among Young Consumers. European Business \& Management. Vol. 4, No. 1, 2018, pp. 39-43. doi: 10.11648/j.ebm.20180401.16

Received: October 11, 2017; Accepted: November 7, 2017; Published: January 9, 2018

\begin{abstract}
Purpose: India is known for highest number of young people in the world. Students as consumers are more dynamic and emerging consumer group for restaurants. Focusing on younger diner attitude and preferences, the aim of this paper is to use factor analysis approach to group different factors influencing their motivation behind dining out in casual restaurants. Total 31 variables were identified based on literature review. Data analysis was done using SPSS 20. Nine factors were identified which had high loadings. The sample for the study was drawn using convenience sampling technique of university students which is a major limitation of the study. Further random sampling may be used taking large sample size for more generalized results. The findings of the study would help the marketers to analyze major factors influencing dining out behavior of younger consumers.
\end{abstract}

Keywords: Consumer Behavior, Casual Dining Restaurants, Factor Analysis, Food Retail

\section{Introduction}

According to a report by the National Restaurant Association of India, due to rise in eating out Indian economy has propelled the restaurant industry to $\$ 48$ billion and is projected to grow at a CAGR of 11 per cent over the next five years to reach $\$ 78$ billion by 2018 . Casual dining and quick service restaurants evidenced $70 \%$ of the organized segment, leaving far behind pubs, bars, clubs and lounges (PBCL) from $12 \%$, cafes take $8 \%$ share remaining fine dining and frozen desert outlets. It has been estimated that in the time to come India will evidence more than 2.1 million outlets providing cuisine that is appealing to different taste buds. The location will be mainly retail, travel, leisure and lodging. The growth in retail and travel is faster and it is expected that it will account for 145,000 and 87000 outlets respectively by 2015 as per Euro monitor estimates. The size of food service industry is expected to be Rs. 62,500 crores by the year 2015 . The growth in overall restaurant industry is at 5\%- 6\% annually. It has been evidenced that Indian consumers are being attracted towards dining out, especially in urban areas. It has been found that about 50 percent of India's populations dine out at least once in every three months. Increased polarization towards urban areas and changing lifestyle, tastes, preference for food and increasing number of females working and eating-out options has given rise to $\mathrm{F} \& \mathrm{~B}$ industry.

Dining out has seen tremendous growth in recent years as people of urban cities have found different reasons to have their food outside their home such as birthday parties, wedding, hangover with friends, celebrating the success as youth celebrates when results are out, reunion and valentine day parties and other occasions are being celebrated by dine out.

As per the India leisure and entertainment report by Knowledge Tree Company dining out has been found as one of the three most popular recreational activities by Indian consumers.

A casual dining restaurant is one which serves moderately priced food in casual atmosphere setting. It comes between fast food establishments and fine dining restaurants.

While deciding on to go for dine out people have endless options from fast food to casual dining restaurants and 
having five star fine dining experience. What factors motivate the consumers to dine out and what attributes make them select specific restaurants? In a study Njite et al., (2008) [8] concluded that previous experience and former knowledge plays a vital role while making a restaurant selection decision. Generally quoted reasons for dining out side at fast food establishments included a way to socialize, convenience such as it is quick and easy to get (Raydell et al., 2008) [10]. Employee competence and convenience and good customer relations were found to as vital factors influencing customer's selection for fine dine restaurant (Njite et al., 2008) [8]. Casual dining has not been explored well by the researchers especially considering youth in India.

As per census of India statistics the number of students in India has reached 315 million. This growth has placed India on second position but also Indian students would make fourth biggest nation in the world.

\section{Literature Review}

Students as diners have not been popular area of research. However, for last few years marketer's interest has drawn attention towards exploring and targeting young consumer group. According to Jenkinson, (2000) [7] it can be considered as potentially lucrative segment and to have long term marketing relationship with them. Having the responsibility to arrange and organize their options for food they heavily depend upon dine out and fast food options which is convenient and easy to get and casual dining also gives them a way to celebrate and socialize with friends. In a study conducted by Baloglu and Uysal (1996) [1] on tourism research suggested that there are two factors as push motivator and pull motivator which encourages and attract an individual to dine out side home. Epter (2009) [5] said in his study that socialization was a common reason to dine out. Special occasion was found as most important reason followed by socializing with friends and convenience for dining out among people in Ireland (Cullen 2004) [2]. Dobson, S., \& Ness, M. (2009) [3] found in their research that student market should not be considered as en-masse since they have different preferences

\section{Need for the Study}

Students are emerging as young consumers in casual dining and the field has yet not been explored extensively. For the marketers of food retail industry it becomes vital to explore their dining out motivation and analyze different attributes they look inside a restaurant.

\section{Objectives}

(1) To identify and group the factors influencing dining out behavior of students.

(2) To find out gender wise, age wise and education wise differences in frequency, preference to dine out in casual restaurant.

\section{Research Methodology}

A questionnaire as a research instrument was developed considering various aspects of students food shopping. It basically included, convenience social interaction, service and quality aspects in regard to casual dining. The sampling method employed convenience sample based on student faculty within the BBD University, Lucknow. The survey was administered on 210 university students from different disciplines such as B. Tech., M. B. A, and PhD. yielded 181 usable responses for the purpose of the study.

The questionnaire was divided into two parts. Part A covered various questions related to their casual dining behavior and Part B covered nominal variable including their demographic details.

The theme concerned with factors related to casual dining restaurants 31 item scales that measured the degree of the importance of these features in context to food shopping ( $1=$ strongly disagree, $5=$ strongly agree).

The theme related to student's demographic attributes included nominal questions such as their age, gender, education, casual restaurant dining frequency in past month and their preferred reason to dine out.

\subsection{Hypothesis}

H1- Demographic factors such as age, gender and education have statistically no significant relationship with casual restaurant frequency.

H2- Demographic factors such as age, gender and education have no positive relation with preferred reason to dine out.

\subsection{Statistical Analysis}

The data analysis was done using SPSS 20.0 version. The sample attributes are presented for their demographic details using frequencies.

Factor analysis is applied to 31 item five point Likert scale concerned with reasons for casual dining and store attributes while selecting a restaurant. Factor scores are saved as variables with respect to their loadings. On nominal variables cross tab and chi square tests were used.

\subsection{Demographic Characteristics}

The sample included $66.7 \%$ females and $33.7 \%$ males, in which $48.6 \%$ post graduate, $40.9 \%$, were under graduate and $10.5 \%$ in their doctoral program. In terms of their visit to their preferred casual dining restaurant $39.8 \%$ visited once, $28.7 \%$ visited 2 to 3 times, $20.4 \%$ visited 4 to 5 times and $11 \%$ visited more than six times in past month. $56.4 \%$ hanging out with friends, $21.5 \%$ on weekend, $10.5 \%$ were found habitual, $6.1 \%$ went for casual dining to celebrate with friends while results were out and $5.5 \%$ on birthdays. 
Table 1. Demographic characteristics of sample.

\begin{tabular}{l|l|l}
\hline Demographics & $\boldsymbol{n}$ & $\boldsymbol{\%}$ \\
\hline Gender & & \\
Female & 120 & 66.3 \\
Male & 61 & 33.7 \\
Age & & \\
18 to 25 years & 157 & 86.7 \\
26 to 35 years & 21 & 11.6 \\
36 years and above & 3 & 1.7 \\
Level of education & & \\
PG & 88 & 48.6 \\
Undergraduate & 74 & 40.9 \\
Doctorate and Above & 19 & 10.5 \\
Restaurant visit frequency for casual dining in past month & & \\
Once in past month & 72 & 39.8 \\
2 to 3 visits in past month & 52 & 28.7 \\
4 to 5 visits in past month & 37 & 20.4 \\
6 and above visits in past month & 20 & 11.0 \\
Preferred reason to dine out & & \\
Hanging out with friends & 102 & 56.4 \\
Weekends & 39 & 21.5 \\
Habitual & 19 & 10.5 \\
Birthdays & 10 & 5.5 \\
After results are out & 11 & 6.1 \\
\hline
\end{tabular}

\subsection{Factor Analysis}

The original variables included 31- item five- point scale concerned with the preference and motivation behind dining out to a casual dining restaurant. The analysis was done using principal component analysis with Varimax rotation and factors having Eigen values greater than one were extracted.

Table 2. KMO and Bartlett's Test.

\begin{tabular}{lll}
\hline KMO and Bartlett's Test \\
\hline \multicolumn{3}{l}{ Kaiser-Meyer-Olkin Measure of Sampling Adequacy. } \\
& Approx. Chi-Square & .754 \\
Bartlett's Test of Sphericity & df & 3786.234 \\
& Sig. & .000 \\
\hline
\end{tabular}

The solution resulted in nine factors. Ten factors were dropped due to cross loading. To confirm that the test variables are inter-correlated is indicated by a KMO value of .754 taking together Barlett's test of sphericity which resulted in chi- square test statistic of 2756.00 with 378 degrees of freedom. It indicates the rejection of null hypothesis, that there is no inter correlation among variables at $5 \%$ level of significance. The solution is presented in the rotated component matrix in table 3 below. Cronbach's Alpha value is .888 .

Table 3. Factors with loadings.

\begin{tabular}{ll}
\hline Factor 1 & Factor Loadings \\
\hline Pleasant aroma inside restaurant & 0.681 \\
Location of restaurant is convenient & 0.626 \\
Restaurant has good lighting & 0.584 \\
Soothing music & 0.501 \\
Factor 2 & \\
Prefers soft drink with food & 0.721 \\
Availability of fast food & 0.576 \\
Factor 3 & \\
Offers special discount to students & 0.721 \\
Price is reasonable & 0.719 \\
\hline
\end{tabular}

\begin{tabular}{ll}
\hline Factor 1 & Factor Loadings \\
\hline Factor 4 & \\
There is some special occasion & 0.830 \\
I am fond of specific food. & 0.827 \\
Factor 5 & \\
I do not have proper knowledge of recipe & 0.795 \\
I do not know how to cook. & 0.768 \\
I do not like cooking food & 0.819 \\
Factor 6 & \\
Availability of promotion coupons and schemes & 0.814 \\
Restaurant promotes itself on face book and other & 0.845 \\
social media sites & \\
Factor 7 & 0.871 \\
Food matches my tastes and dietary requirements & 0.574 \\
Restaurant serves special requirements & \\
Factor 8 & 0.828 \\
Washing dishes is monotonous work & 0.703 \\
Cooking is tedious work & \\
Factor 9 & 0.834 \\
Service is consistent inside restaurant & 0.595 \\
Food quality is good &
\end{tabular}

The solution was obtained using cumulative variance and communalities. Approximately 72 percent of total variance was explained nine factors. The first factor is strongly correlated with pleasant aroma inside restaurant, location of restaurant is convenient, restaurant has good lighting, soothing music, is defined as store oriented dinners. The second factor is associated with prefers soft drink with food, availability of fast food, it can be said as fast food seekers. The third factor emerged with high correlated variables as offers special discount to students, price is reasonable, which is defined as prudent dinners. The fourth factor consists of there is some special occasion, I am fond of specific food can be named as specialty dinners. The fifth factor highly correlated with I do not have proper knowledge of recipe, I do not know how to cook, I do not like cooking food which can be called as cooking novices. In factor six variables such as availability of promotion coupons and schemes and restaurant promotes itself on face book and other social media sites were found positively correlated. They can be put under social media savvy. Food matches my tastes and dietary requirements and restaurant serves special requirements shown high correlation under factor seven which can be put under factor food portion seekers. Washing dishes is monotonous work and cooking is tedious work were clubbed in one factor which can be put under culinary dislike. Service is consistent inside restaurant and food quality is good were found closely associated with each other which can be put under factor quality conscious dinners.

Education was also found to have no relationship with casual restaurant dining frequency since (chi- square $=7.909$ $\mathrm{df}=6, \mathrm{p}>0.001$. There was also evidence of no significant difference between age and casual restaurant dining visit frequency (chi- square $=17.563 \mathrm{df}=6, \mathrm{P}>0.001$. thus it can be concluded as that male and female students behave similarly while dining out in casual restaurant. Education was also found to have no impact on dining out.

Dining out preference was also not associated with age (chi- square $=14.381 \mathrm{df}=8, \mathrm{p}>0.001$. Gender also has no 
significant difference with preferred reason to dine out (chisquare $=6.983, \mathrm{df}=4, \mathrm{p}>0.001$. There was also no significant difference between education and preferred reason to dine out $($ chi-square $=10.029 \mathrm{df}=8, \mathrm{p}>0.001$.

\section{Results and Discussion}

\section{Demographics}

Total 181 usable responses were gathered by the researcher. The sample population consisted of university students. Mostly students were from 18 to 25 year age group which could be expected as the survey was done among university students. Zalatan in 1998 [11] found in his research that women were dominant and played key role in family's purchase decision over past two decades. Its gives a clear representation for their higher purchases potential. Therefore the majority in female respondents considered for research is relevant. In his study Greenberg (2012) [6] concluded that student spend $\$ 13$ billion on dining out at casual restaurants in 2011 which gives a base to choose college students as relevant sample for the study. The variables for the research were taken after extensive literature review. Factor analysis reduced 31 variables to 9 factors.

Objective 1: To identify and group the factors influencing dining out behavior of students.

The factors scale and factor within this research were taken from Jennifer L. Duncan et al.'s (2014) [4] study on segmenting patrons of casual dining research and some from literature review in relevant area of research. The basic factors were found as store oriented dinners, fast food seekers, prudent dinners, specialty dinners, cooking novices, social media savvy, food portion seekers, culinary dislike, quality conscious dinners.

Objective 2: To find out gender wise, age wise and education wise differences in frequency, preference to dine out in casual restaurant.

The cross- tab analysis and chi-square was used to examine the relationship between demographic characteristics of young diners and their frequency to dine out and preferred reason. There was no significant difference found in male and female diners when analyzing their frequency to dine out and preferred reason. Therefore, we can say that both of them behave similarly while dining out in casual restaurant.

\section{Conclusion}

The use of factor analysis offers reducing the variables and clubbing various factors which are highly correlated and allows the marketers to have specific direction to take decision. In the study basically nine factors were found after factor analysis. It gives a clear insight towards dining out motivation of young consumers in casual restaurant. As far as the differences in male and female are concerned regarding their frequency to visit and reason to dine out, they behaved in similar fashion while going to dine out. It gives a clear understanding that marketers should not differentiate while making their offering to young diners in terms of discussed factors.

To sustain in restaurant business attracting consumers is vital. The results of this study can be utilized by the restaurants while devising marketing strategies to attract young diners. Store oriented dinners put more stress on aspects of physical and atmospheric ambiance of the store. For fast food seekers, it is advised to have offering which is not heavy on their pockets and quickly available. Prudent dinners enjoy dinning out in restaurants which offers discounts and seek good value. Specialty dinners need to be taken care of by offering specific cuisine. The cooking novices do not enjoy cooking and therefore, they avoid and prefer to dine out side.

Social Media Savvy dinners are interested in browsing information related to food on social media sites. Nusair et al. (2013) [9] said in their study that college students are highly technologically savvy and heavy users of social media websites. They want stress on promoting the restaurants on different social media websites. Food portion seekers are highly conscious towards their dietary requirement. Culinary dislikes are the consumers who feel monotonous and avoid cooking food by their selves. Quality conscious dinners would prefer restaurants which offer good quality food and consistency in service. Hanging out with friends was found as major reason behind dining out in casual restaurants by the students $56.4 \%$ followed by weekends $21 \%$. Its gives a clear picture that socialization is a major reason for dining outside home.

\section{Limitations and Further Research}

The study was basically conducted in university campus, and due to limitation of time convenience sampling technique was adopted to draw the sample. Although it gives the clear findings but the differences may exist with of campus students. Therefore, a more comprehensive study taking a large sample should be attempted. As the demographics factors differ country to country the results may not be generalized.

\section{References}

[1] Baloglu, S., \& Uysal, M. (1996). Market segments of push and pull motivations: A canonical correlation approach. International Journal of Contemporary Hospitality Management, 8 (3), 32-38.

[2] Cullen, F. (2005). Factors influencing restaurant selection in Dublin. Journal of Foodservice Business Research, 7 (2), 5385 .

[3] Dobson, S., \& Ness, M. (2009). Undergraduate students' attitudes towards food shopping and attitudes to time. International Journal of Consumer Studies, 33 (6), 659-668.

[4] Duncan, J. L., Josiam, B. M., Kim, Y. H., \& Kalldin, A. C. (2015). Using factor-cluster analysis to segment patrons of casual dining establishments in the United States. British Food Journal, 117 (4), 1377-1398. 
[5] Epter, A. (2009). Eating Out in Modern American Society: Why Do People Make the Choice to Eat Outside the Home?

[6] Greenberg, K. (2012). College students discretionary spending way up.

[7] Jenkinson, E. (2000). Carry on campus. Checkout, February, $20-1$.

[8] Njite, D., Dunn, G., \& Hyunjung Kim, L. (2008). Beyond good food: What other attributes influence consumer preference and selection of fine dining restaurants? Journal of Foodservice Business Research, 11 (2), 237-266.
[9] Nusair, K. K., Bilgihan, A., \& Okumus, F. (2013). The role of online social network travel websites in creating social interaction for Gen $\mathrm{Y}$ travelers. International Journal of Tourism Research, 15 (5), 458-472. doi:10.1002/jtr.1889

[10] Rydell, S. A., Harnack, L. J., Oakes, J. M., Story, M., Jeffery, R. W., \& French, S. A. (2008). Why eat at fast-food restaurants: reported reasons among frequent consumers. Journal of the American Dietetic Association, 108 (12), 20662070 .

[11] Zalatan, A. (1998). Wives involvement in tourism decision processes. Annals of Tourism Research, 25 (4), 890-903. 